\title{
ENTREVISTA CON DR. JUAN PEDRO RUIZ SANZ
}

\author{
Entrevistadores: \\ Fabio Angeoletto \\ fabio_angeoletto@yahoo.es \\ Universidade Federal de Mato Grosso, Rondonópolis, MT \\ Gedeone Ferreira Lima \\ gedeone_ferreira@hotmail.com \\ Universidade Federal de Mato Grosso, Rondonópolis, MT
}

\section{"Necesitamos, simplemente, imaginar lo impensable. Y hacerlo posible. Solo eso"}

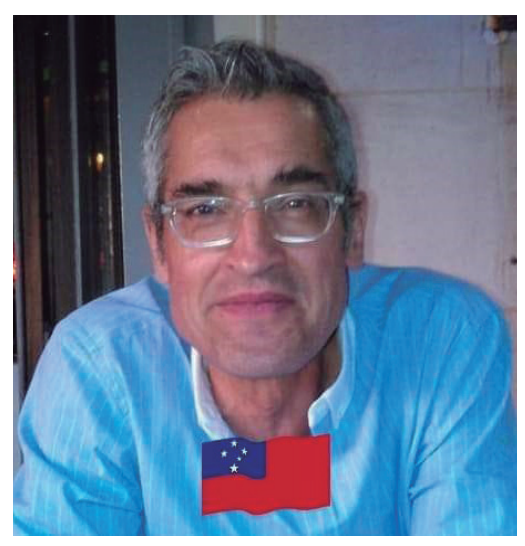

Dr. Juan P. Ruiz es profesor titular de Ecología en la Universidad Autónoma de Madrid. Estudió Zoología y Planificación Rural e hizo un doctorado sobre la etnoecología de los ganaderos de la Sierra de Madrid. Imparte clases de Ecología Humana, Evaluación y Gestión del Paisaje y Seminario Interdisciplinar sobre Desarrollo y Medio Ambiente en los grados de Biología y Ciencias Ambientales. Siempre le interesó la ciencia en las fronteras Interdisciplinares, el papel de la ciencia en educación, la relación entre literatura, ciencia y filosofía, la ecología política y los grandes debates sociales de nuestro tiempo. Ha hecho investigación aplicada sobre evaluación, percepción y planificación participativa del paisaje en España, Australia, Venezuela, Cuba, América Central, Colombia y Brasil con una docena de tesis doctorales dirigidas. En la actualidad escribe la novela definitiva sobre el Poder, la crisis ambiental global, la inteligencia artificial en una trama de detective sobre una crisis mundial en la globalización. (Aunque el virus le ha dejado la crisis de ficción muy disminuida y le obligará a reescribir, como a toda la humanidad). Su foto incluye la bandera de Samoa Occidental porque se identifica con Robert Louis Stevenson y su epitafio en su casa de Vailima, que tuvo la oportunidad de visitar en su aventura vital de explorar/impactar la Biosfera: "under the wide and starry sky dig the grave and let me lie... Home is the sailor, home from sea, and the hunter, home from the hill". Esos versos y el poema del también escocés Robbie Burns "To a mouse" resumirían su biofilia, su curiosidad por el universo y su empatía biosférica. Es padre, anarquista y mediterráneo. 
Terr@Plural - La Ecología Urbana tuvo un gran impulso, tanto en número de científicos, como en conocimiento producido, a partir de 1990. ¿Cómo definiría usted esta ciencia?

Ecología urbana es el zoom de la Ecología hacia los ecosistemas urbanos. Se prevé que en 2050 más del $60 \%$ de la humanidad viva en ciudades, unos cinco mil millones de personas, y que las urbes contribuyan en dos tercios de las emisiones que causan efecto invernadero y cambio climático. Y eso solo en menos del uno por ciento de la superficie del planeta. Las mayores cien ciudades dan lugar ya al 20\% de las emisiones según un estudio en Scientific American en 2018. En los últimos años China ha consumido más cemento que los USA en un siglo. Son algunos indicadores del tamaño de la cosa. Los dos grandes problemas de la humanidad son la inequidad y el cambio climático. Avances en Ecología urbana son por tanto indispensables en la crítica situación de la Biosfera humanizada.

Cuando aplicamos estas etiquetas a sustantivos muy cargados de significado como es el de Ecología hay que entender que los ecosistemas son un continuo y la naturaleza no sigue dócilmente nuestras distinciones conceptuales. Así hablamos de Ecología humana o urbana para entendernos y para enfatizar que los estudios en ciudades han sido relegados por los ecólogos, que han favorecido escudriñar en los ecosistemas "naturales". Pero este es un enfoque humano, la vida no hace esas distinciones. Para la Biosfera nosotros y nuestras ciudades somos naturales, un "mero" producto de la evolución. El problema no es la supervivencia de la Biosfera, eso está garantizado hasta la expansión del sol a gigante roja dentro de cinco mil millones de años. La cuestión es si la Tierra mantendrá los estándares bioclimáticos, productivos y de biodiversidad que precisamos nosotros para sobrevivir y que la vida valga la pena.

Terr@Plural - Los datos apuntan que, a pesar de las megaciudades, la mayor parte del crecimiento urbano, en términos globales, ocurre en ciudades pequeñas y medianas, cuya capacidad de planificación y gestión es usualmente baja. ¿Está usted de acuerdo con este punto de vista? ¿Y cómo la Ecología urbana puede ser aplicada para disminuir los impactos de esas urbes y para aumentar la calidad de vida de sus ciudadanos?

Este enfoque parece correcto y los desafíos en planificación y gestión son enormes. Se precisa un conocimiento efectivo que permita desarrollar urgentes planes para una gestión ecológica con conocimiento y participación de los ciudadanos. Ese, sin embargo, es un mantra que se viene repitiendo desde hace años sin avances efectivos. Aunque es justo decir que se están dando experiencias a pequeña escala muy útiles. La ciencia no está avanzando en la medida que se requiere y la participación ciudadana, o el "urbanismo desde abajo" que se viene invocando es ya un lugar común pero no tiene, ni de lejos, ni la dimensión ni la capacidad de gestión para hacer frente a los retos. La planificación y el diseño participativos pueden mejorar la calidad de vida urbana como podemos ver en los ejemplos de Reinventar París o Peatonalizar Broadway. Estamos hablando de ciudades en las que respirar puede llegar a equivaler a fumar cincuenta cigarrillos al día como se dice que es el caso de Delhi. La esperanza de vida puede variar entre barrios de una ciudad en 
diez años o más como en Hong Kong o Madrid. Y la salud correlaciona positivamente con la extensión del verde urbano. Estas son cuestiones sin duda vitales en las que habremos de trabajar mucho. Pero las ciudades, focos tan creativos como problemáticos en la historia de la humanidad, se insertan en la Biosfera. Y tendremos que encontrar respuestas a escala planetaria.

Terr@Plural - Vivimos en el Planeta Ciudad. El futuro es urbano, pero probablemente la distopía presentada en la película clásica de ciencia ficción Blade Runner (jcuya historia tiene lugar en 2019!) No se materializará. ¿Cómo vislumbra el crecimiento de las ciudades a lo largo del siglo XXI? ¿Alcanzaremos los objetivos aparentemente inconciliables de desarrollo urbano, conservación de la biodiversidad urbana y disminución de la huella ecológica de las ciudades?

Como afirma la frase cínica es muy difícil predecir, particularmente el futuro. Para poner en contexto el futuro de las ciudades en este siglo debo referirme al marco global, el de la Biosfera humanizada. Y me temo que no tengo buenas noticias. A principios de este siglo la expansión increíble del mundo virtual nos hizo pensar a algunos que la toma de decisiones en las sociedades humanas iba a hacerse descentralizada y en democracias directas que recuperarían la ecología política anarquista de nuestros ancestros cazadoresrecolectores. Nos engañamos. Occupy Wall Street, la primavera árabe o el $15 \mathrm{M}$ en España han acabado como tragedias o como farsas. La desinformación, la manipulación y los Fake News imperan y con ellos el auge de fenómenos, que serían risibles si no fueran tan peligrosos, como Trump, Bolsonaro, la extrema derecha, el Brexit o el populismo supuestamente izquierdista. No quiere decir que la batalla esté perdida a más largo plazo pero no vamos nada bien. Y esto antes de que la realidad virtual se use tanto como experiencia transformadora como el mecanismo de alienación y adicción última de las masas.

Este largo preámbulo es para decir que lo que se ha llamado gobernanza de las sociedades sigue siendo el punto crucial y que tenemos el deber hoy más que nunca de alzar la voz con verdades sumamente inconvenientes. Y la más clara es esta: con los procesos socioeconómicos y políticos actuales todo indica que la humanidad no podrá hacer frente a la crisis climática que estamos provocando. El Acuerdo de París se basa en una noción de "economía verde" que se parece mucho a soñar con unicornios. Elucubrar que podremos sustituir una curva creciente de emisiones con llegar a cero en las próximas décadas y hacerlas negativas, descarbonizar la economía, es puro pensamiento mágico con los abordajes actuales. Ni las técnicas necesarias ni los mecanismos sociales están no ya operativos sino ni siquiera en la mesa de diseño. Ni están ni se les espera. Un reciente artículo en la revista New Political Economy deja muy desnudo al proverbial emperador de la "economía verde".

Dicho esto la implicación es tan obvia como utópica, o distópica: estabilizar el planeta es estrictamente incompatible con la noción de crecimiento económico que postulan tanto el capitalismo como el socialismo. Eso son palabras mayores y soy consciente de lo que estoy diciendo. ¿Cómo serán en este contexto las ciudades del siglo XXI? Probablemente nada tan heavy, ni tan perversamente bello, como Blade Runner pero o bien sitios muy 
difíciles de imaginar en una economía trans-crecimiento o bien ecosistemas críticos en un mundo incapaz de pagar sus facturas ambientales. Ni las de equidad, que tampoco van por buen camino.

Terr@Plural - ¿Los conocimientos que usted ha producido sobre Ecología Urbana son de algún modo traducidos en planificación y gestión? En su país, ¿hay una cooperación efectiva entre gestores, para aplicar la ecología urbana a la planificación?

Esta pregunta tiene una respuesta no sé si pesimista pero un tanto escéptica. En términos realistas mi trabajo de formación se ha dirigido a miles de estudiantes y otras audiencias y a una docena de doctorandos, que no creo tengan posibilidades reales de hacer cambios sustanciales en la sociedad en el contexto socio-económico y político que describía antes. Suponiendo que mis argumentos les hubieran influido en alguna medida. En España como en el resto de países desarrollados y en los países del Sur ha habido interesantes experiencias en nuevas tecnologías, arquitectura, urbanismo y gestión ambiental, sin duda, pero cuando se ponen en relación con la escala del problema estamos muy lejos de poder enfrentar los retos. Es como atajar una gran hemorragia con tiritas sanitarias. El problema es que ni los políticos, ni los decisores, los Illuminati u otros más pedestres, ni los comunicadores, ni la sociedad en su conjunto son conscientes de ello. Y de hecho se van a hacer todos los esfuerzos posibles para ignorar esta realidad. No le conviene a nadie saber la magnitud del riesgo en el que incurrimos. Eso no me lleva a un pesimismo paralizante. Los seres humanos estamos diseñados para evitar las malas noticias. Pero cuando estas se hacen insoslayables también tenemos en nosotros la capacidad para luchar. Que está pugna sea mínimamente planificada y no desesperada es el verdadero desafío.

Durante décadas ha habido intensas discusiones entre los expertos entre los defensores de la sostenibilidad "blanda", ajustes asumibles por el modelo socioeconómico, y los partidarios de la sostenibilidad "dura", cambios radicales del mismo. Creo que un juicio ecuánime de la situación actual es que la sostenibilidad blanda no es suficiente y la sostenibilidad dura no es posible. Menuda barbaridad acabo de lanzar. Es decir estamos como en la expresión inglesa entre el diablo y el mar azul. En castellano decimos entre la espada y la pared. En un bloqueo. Y no es un sitio cómodo donde estar cuando nos jugamos tanto. Y en estas llegó el virus.

Hace unos meses apenas esperábamos el final esperadísimo de la saga de Juego de Tronos, o el final del Brexit, que resultó desastroso, o la siguente estupidez con gran riesgo para la humanidad de Trump, Johnson o Bolsonaro. Eso era lo que llamábamos "normalidad". Hoy un cisne negro inesperado nos ha traído la mayor crisis sanitaria, económica y social para la humanidad en al menos un siglo. La lógica profunda del coronavirus es la misma que la de la Crisis Ambiental Global y la Emergencia Climática. Tocamos los límites de la Biosfera con nuestro tecnometabolismo en esta fase de la historia ecológica de la humanidad y la naturaleza nos devuelve el feedback en forma de riesgos incrementados inasumibles. Este mensaje tan claro no va a llegar a los políticos, decisores, periodistas y población. Intentaremos volver cuando antes a que vuelen los aviones por 
nuestros cielos silenciosos y recuperar el business as usual. De hecho no sabemos resolver los problemas de producción de bienes y servicios, consumo, empleo, bienestar, la propia salud de otra manera. Hay pensadores "buenistas" que aventuran que esta es nuestra oportunidad para aprender la lección, tomar el timón y cambiar el rumbo. Yo no tengo la bola mágica de cristal, no veo el futuro en esta niebla espesa, no soy Nostradamus, pero mi feeling es más bien escéptico. Si la Biosfera no nos envía un aviso más serio aún, del que el virus sería apenas el primer mensajero de "las siete plagas", no creo que sea factible la operación social gigantesca de afrontar la profunda inequidad de los humanos y la descarbonización de la economía. Sin estas operaciones tan fundamentales como utópicas a día de hoy en el mundo tras el coronavirus, que por cierto tiene posibilidades de convertirse en los próximos meses en un colapso económico y social y una catástrofe humanitaria en el Tercer Mundo de gran magnitud, no podremos enfrentar con un mínimo de garantías el siglo XXI.

Terr@Plural - La diversidad biológica de las ciudades es uno de los temas centrales de investigaciones de los ecologistas urbanos. ¿Cómo los ciudadanos comunes pueden ser comprometidos en acciones de conservación de la biodiversidad urbana?

Hace mucho que no creo ni en la educación ambiental ni en las soluciones individuales. Si bien la decisión personal sobre un estilo de vida menos consumista e incluso retirarse a la naturaleza en plan buen salvaje de Rousseau es muy respetable eso no va a cambiar el futuro de la humanidad. Siento desanimar a los "certinhos", en Portugués, de todos los pelajes. Los cambios en ciencias naturales y sociales simplemente no funcionan así. Hay que trabajar en Educación, con mayúscula, que sigue siendo el gran medio para empoderar a los individuos y a los colectivos. Por todos los medios, particularmente las nuevas tecnologías, y luchando contra la desinformación e intoxicación en las redes. En el nuevo mundo feliz virtual, esa maqueta del mundo borgiana a escala uno a uno, que nos hemos inventado. Pero eso no va a ser una solución milagrosa. El objetivo es un cambio social y económico que no tiene comparación en la historia reciente de la humanidad: encontrar una alternativa al paradigma de crecimiento. $Y$ hacerlo sin forzar más allá de límites intolerables la maquinaria de la Biosfera. $Y$ hacerlo sin incrementar la ya inadmisible inequidad entre los humanos. Y hacerlo soslayando amenazas de conflictos bélicos de proporciones ingentes. En resumen, probablemente el mayor desafío que ha enfrentado nunca nuestra especie.

No soy optimista ni pesimista. Me gustaría ser realista. Y este es el diagnóstico más honesto que puedo hacer de la situación. Los ciudadanos pueden comprometerse con la biodiversidad urbana de muchas maneras. Y eso será bueno. Esperemos que estar un poco más cerca de la vida contribuya a que se hagan idea del juego de la Biosfera y de cómo estamos haciendo trampas. Y que este sea el terreno abonado para las semillas del cambio. Para empezar a pensar colectivamente en lo impensable: que el maravilloso show de Truman que nos hemos montado en las sociedades desarrolladas a costa de los pobres del planeta y del futuro de nuestros hijos no va a funcionar. Que se resquebraja. Y 
que tenemos que concebir y llevar al mundo real formatos de decisión social, tecnologías y procedimientos económicos nunca probados antes. Y que el tiempo va en nuestra contra, que a medida que nos metamos más profundo en la ciénaga la crisis será más profunda y las soluciones más desesperadas. Que lo importante a medio y largo plazo tiene que dominar en la agenda a lo urgente, lo que va completamente a contrapelo del diseño evolutivo de nuestro cerebro. $Y$ hacer toda esta empresa de auto-transformación de nosotros mismos con mecanismos viables sociales, económicos y políticos que mantengan, y mejoren nada menos, los derechos humanos básicos, el empleo y la calidad de vida.

Esto es en esencia lo que implica el concepto de desarrollo sostenible. Otro mantra de los ochenta que ha funcionado hasta ahora como una palabra mágica, un abracadabra. Es preciso dotarla de sentido más allá del deseo infantil de seguir "desarrollándonos" sin pagar los costes ambientales y sociales en que la señora termodinámica nos hace, necesariamente, incurrir. En gallego hay una frase que lo ilustra muy bien: todos queremos "la vaquiña sin cornos", lo que en castellano llamamos un chollo, un milagro. Los anglosajones lo expresan más fríamente: las "comidas gratis" no existen. Puro segundo principio de la termodinámica. Maduraremos desde la primera infancia de la humanidad cuando superemos el pensamiento mágico que nuestra sociedad de consumo potencia cada minuto de nuestras vidas. Ahí es nada.

Terr@Plural - ¿Cuál es el futuro de la ecología urbana?

Como decían en Terminator, 4 creo que era, "el futuro no está escrito". En el panorama que he descrito, que a algunos les parecerá apocalíptico, necesitaremos mucha Ecología y mucha Educación y mucha Tecnología y mucha Democracia, si la podemos rescatar del lodazal en que la hemos sumergido con tantas decisiones sociales terribles o banales. Todas con mayúscula. Y necesitaremos mucha buena suerte.

Seguro que alguna civilización que pasó por algo parecido y, de alguna forma, lo superó nos está observando a millones de años luz en el Cosmos infinito. Tan infinito como la estupidez humana, según dicen en Facebook que dijo Einstein. Quizá se rían a carcajadas, quizá nos usen como un reality show, quizá hagan apuestas. Podrían enviarnos algún truquito los muy puñeteros. O tal vez haya por ahí algún dios menor en paro al que le podría encajar redimirnos de nuestra triste y arrogante condición. Pero me temo por lo silencioso que está el cielo últimamente que tendremos que salir de esta nosotros solos. Nadie dijo que fuera fácil. La evolución no nos diseñó para ser felices, nos diseñó para sobrevivir y reproducirnos. Hasta ahora hemos tenido un éxito brutal como especie dominante y candidata a la autodestrucción. Tenemos ahora la necesidad, y la oportunidad, de usar nuestro flamante cerebro para algo profundamente contra-intuitivo: actuar con sensatez. Necesitamos, simplemente, imaginar lo impensable. Y hacerlo posible. Solo eso. 
Terr@Plural - En los últimos años, el valor de los espacios verdes urbanos ha crecido significativamente. Grandes noticias para la biodiversidad, pero hay un revés: la gentrificación verde. ¿Cómo democratizar el acceso a las zonas verdes para los urbanitas, independientemente de su clase social?

Los espacios verdes siempre han tenido un valor para la humanidad en términos del instinto, mal estudiado pero innegable, de "fitofilia". Recordemos que la palabra paraíso viene del persa "pardes", una finca cerrada de caza solo accesible para los reyes y poderosos, a través del griego "paradeisos". En la situación previa a la crisis del virus se daba un proceso, en España, lento e insuficiente, de revalorización del verde urbano en términos de acceso a un consumo de naturaleza sofisticado y, mucho menos, de sostenibilidad. En el momento álgido de la crisis se da la increíble paradoja de que mientras países como Bélgica aconsejan el deporte al aire libre con distanciamiento en otros, como España, mantienen a la población en un verdadero arresto domiciliario con consecuencias futuras muy peligrosas sobre la salud biopsíquica de la población. Ahora todos los gurús e "intelectuales" han desempolvado la bola de cristal para tratar de ver lo que nos aguarda tras la bruma. La mayoría dice banalidades o rescata su narcisismo en términos de "ya lo había dicho yo y es el fin o el auge del capitalismo según mi particular manía". Tiendo a ser escéptico de que algo bueno vaya a salir de todo esto como plantean los "buenistas" que han brotado como flores esta primavera en el hemisferio Norte. Si miro al futuro veo que la noción de "normalidad", que ya era tóxica antes, se va a replantear. El virus no es más que una manifestación de cómo la naturaleza juega al feedback, ley del universo, con nosotros ante nuestra transgresión de sus límites para una Biosfera humanizada. Este es, apenas, un caso particular de las crisis que nos aguardan este siglo en el contexto de la Inequidad insostenible de la humanidad, la Crisis Ambiental Global y la emergencia climática. En todo este complejo y confuso contexto vamos a necesitar más que nunca el verde urbano en unas vidas en crisis. La demanda de salud biopsíquica va a existir y crecer. Cómo se va a gestionar esa demanda y esa necesidad debería relacionarse con una gestión comunitaria participativa que apenas ha sido un mantra durante las últimas décadas. Ahora va a ser necesaria de verdad. Y urgente.

Terr@Plural - La pandemia de Covid-19 es urbana y afectará principalmente a los urbanitas. ¿Cómo se podrían explicar las altas tasas de infección y letalidad en un país como España?

Con la ayuda de una cachaça brasileira que tenía por ahí tuve una iluminación. El virus se ha cebado en España y en otros países por dos factores fundamentales y relacionados: movilidad y concentración de la población. En movilidad se incluyen la intra-ciudad, la intranacional y la que salta fronteras. La primera se agrava con el transporte público concentrado frente al coche individual, como en Madrid y Nueva York frente a los Ángeles, y afecta desproporcionadamente a los más pobres que no tienen la alternativa del teletrabajo. La segunda parece haber sido alta en España los días anteriores al confinamiento y procede de una organización previa tóxica del uso del territorio con la segunda residencia. La transfronteriza muestra el grado de movilidad entre España y sus países vecinos en lo 
que llamábamos la "normalidad". Así entró el virus cuando ingenuamente, y sin ninguna capacidad de previsión pues a diferencia del Oriente no teníamos ninguna "vacuna social" en Europa Occidental frente a estas crisis, perfectamente anunciadas pero imposibles de precisar, ni nos imaginábamos una transmisión comunitaria a principios de marzo cuando campaba desde febrero. Entró por unas fronteras muy abiertas, que territorios insulares como Nueva Zelanda y Taiwan cerraron, y se distribuyó en centros urbanos concentrados en transporte y aglomeración social cultural. Por esta movilidad que "era" básica en nuestra forma "normal" de vivir entró y se dispersó muy eficazmente el virus por España.

El virus moral como estableció La Peste de Albert Camus cabalga paralelo en peligrosidad al biológico y a diferencia de este, que es intrínsecamente "inocente", se basa en dos cualidades muy humanas: la ignorancia y la iniquidad.

La lección que debería aprenderse para el futuro es que solo ha funcionado en algunos países y territorios una estrategia efectiva, para la que vemos a toro pasado que no estábamos preparados socialmente en absoluto a todos los niveles: ciudadanos, autonomías (que tienen las competencias de sanidad transferidas en exclusiva, lo que ahora revela el tremendo abismo de gestión y disfuncionalidad de nuestra querida "España de las Autonomías", además de las políticas que rayan en lo criminal de erosión de la sanidad pública con ejemplos como Madrid y Cataluña bajo gobiernos conservadores y privatizadores, gobierno central, Unión Europea e instituciones supranacionales. Esta consiste en la capacidad de ejecutar testes masivos y tempranos, identificación y aislamiento de contagios y contactos y hubiera podido evitar la transmisión comunitaria que nos ha llevado a un encierro indiscriminado con gigantescos costes psicológicos, económicos y sociales. Y eso bajo tecnologías de información y geolocalización por GPS que efectivamente ponen en cuestión derechos de intimidad que tenemos como sagrados en Occidente pero que han revelado su eficacia en el modelo de Corea del Sur.

Vivimos una "normalidad" en que la tasa de natalidad no compensa la de mortalidad, en que es más difícil hacer reproducirse a los españoles que a los osos panda. Sociedades envejecidas en las que encerramos a los mayores, que nos sobran en nuestras vidas competitivas y consumistas en instituciones que se han convertido en negocios privados favorecidos una vez más por gobiernos conservadores y favorecedores de la rapacidad. En un equilibrio mezquino de instalaciones hosteleras más que asistenciales, personal mal cualificado y mal pagado y lo que las familias pueden pagar para colocar a sus ancianos. Un sistema que se ha revelado cogido con alfileres y enormemente vulnerable ante una crisis de estas dimensiones (la pandemia de coronavirus). Como la propia sanidad pública que ha revelado su extrema fragilidad empeorada por recortes y privatizaciones. Como un sistema "educativo" al que sólo se le ocurre hacer deberes on line para "no perder" un muy estúpido y sacrosanto temario en vez de coger el toro por los cuernos y usar esta gigantesca crisis como una gigantesca oportunidad educativa, poniendo a la comunidad a investigar y comunicar por Internet la propia crisis. Aprendiendo a entender y adaptarse a las crisis que es un objetivo básico de la educación en el siglo XXI. Ante lo que vendrá, esto no es más que una avanzada de la Crisis Ambiental Global y la Emergencia Climática. Por esos senderos va mi novela. 
Terr@Plural - Usted me consta que ha reflexionado sobre las implicaciones de la presente crisis sobre la educación, ¿podría transmitirnos sus impresiones?

Pues una forma de expresarlo es reproducir el texto que les he mandado a las tutoras del colegio e instituto de mis hijos, el siguiente email:

"Hola, soy el padre de un estudiante de tu clase y tutoría y profesor de ecología en la Universidad Autónoma de Madrid, muchas gracias por vuestro esfuerzo y por vuestra actitud. Una cosa tan evidente que me maravilla que no haya ocurrido es que a todos los niveles, desde escuelas e institutos al ministerio de educación, no se haya ni considerado la obvia idea de hacer de la crisis actual el eje de las actividades educativas online y en el curso próximo. Estos niños y jóvenes se van a enfrentar en sus vidas en este siglo a numerosas crisis, naturales e inducidas por los humanos, en particular la emergencia climática, y la gran lección de la crisis es justo empezar a aprender de esa Imprevisibilidad, que varias generaciones anteriores nunca hubiéramos podido ni imaginar, y de la flexibilidad y pragmatismo que van a precisar para afrontar sus vidas. Yo diría que aprender a gestionar crisis va a ser lo fundamental de su educación. Cada uno a su nivel, porque hay temas muy duros de sufrimiento y muerte que a ciertas edades les va a costar asumir, por qué no se afrontan las matemáticas con las curvas y estadísticas epidemiológicas y económicas, la biología con el concepto de virus e infección, la historia con las epidemias históricas, la ecología con las agresiones a la naturaleza de la que las enfermedades emergentes son apenas un ejemplo, la geografía con la distribución por países, autonomías y ciudades de la pandemia, el lenguaje con los relatos periodísticos, políticos e informativos de la ciencia, la literatura con La Peste de Albert Camus y otras obras reveladoras, la economía y la sociedad con los datos y los escenarios, etc., etc. Es decir aprovechar esta gigantesca crisis como una gigantesca oportunidad para una educación significativa, que se supone por todos los pedagogos y autoridades es el objetivo de la educación en el siglo XXI. Algo, que a diferencia de los temarios rígidos, memorísticos y alejados de la realidad que caracterizan lo que llamamos "educación", tenga una relación estrecha con sus vidas, intereses y circunstancias. Algo que ellos puedan en confinamiento explorar, investigar, elaborar y compartir por medio de Internet que debería ser la maquinaria, taller y aula de aprendizaje en el siglo XXI. En fin, me ofrezco a colaborar en todo lo que pueda en cualquier iniciativa en este sentido, repito mi aprecio y agradecimiento por lo que hacéis en circunstancias tan difíciles y te agradecería enormemente que transmitas este mensaje al cuerpo de profesores a la jefatura de estudios y a la dirección de la escuela." Creo que este mensaje expresa muy claramente un punto de vista sobre la educación que para mí debería ser obvio y no lo es.

Y ya sabes, como decía Manoel de Barros el noventa por ciento de lo que escribo es inventado, solo el diez por ciento es mentira. Muchas gracias por las atinadas preguntas. Las cuestiones pertinentes suelen importar tanto como las respuestas. Sé que me he ido de las ciudades a la Biosfera. Pero creo que ese es el viaje que debía hacer. 